\title{
F. novicida-Infected A. castellanii Does Not Enhance Bacterial Virulence in Mice
}

\begin{abstract}
Mateja Ozanic ${ }^{1}$, Ivana Gobin ${ }^{1}$, Martin Brezovec ${ }^{1}$, Valentina Marecic ${ }^{1}$, Zlatko Trobonjaca ${ }^{2}$, Yousef Abu Kwaik ${ }^{3}$ and Marina Santic ${ }^{1 *}$

${ }^{1}$ Department of Microbiology and Parasitology, Faculty of Medicine, University of Rijeka, Rijeka, Croatia, ${ }^{2}$ Department of Physiology and Immunology, Faculty of Medicine, University of Rijeka, Rijeka, Croatia, ${ }^{3}$ Department of Microbiology and Immunology and Center for Predictive Medicine, College of Medicine, University of Louisville, Louisville, KY, USA
\end{abstract}

Francisella tularensis is a facultative intracellular bacterium that causes tularemia in humans and animals. Epidemiology of tularemia worldwide is often associated with water-borne transmission, which includes mosquitoes and amoebae as the potential host reservoirs of the bacteria in water environment. In vitro studies showed intracellular replication of $F$. tularensis within Acanthamoeba castellanii and Hartmanella vermiformis cells. While infection of amoeba by Legionella pneumophila has been shown to enhance infectivity of $L$. pneumophila the role of $F$. tularensis-infected protozoa in the pathogenesis of tularemia is not known. We used $6 \mathrm{~h}$ coculture of $A$. castellanii and F. novicida
OPEN ACCESS

Edited by:

Brice Rotureau,

Institut Pasteur, France

Reviewed by:

Dennis Metzger

Albany Medical College, USA

Gregory T. Robertson,

Colorado State University, USA

Jason Farlow

Farlow Scientific Consulting Company,

USA

*Correspondence:

Marina Santic

marina.santic@medri.uniri.hr

Received: 18 January 2016 Accepted: 03 May 2016 Published: 18 May 2016

Citation:

Ozanic M, Gobin I, Brezovec M, Marecic V, Trobonjaca Z, Abu Kwaik Y and Santic $M(2016)$

F. novicida-Infected A. castellanii Does Not Enhance Bacterial Virulence in

Mice.

Front. Cell. Infect. Microbiol. 6:56. doi: $10.3389 /$ fcimb.2016.00056 for investigation of the effect of inhaled amoeba on the pathogenesis of tularemia on in vivo model. Balb/c mice were infected intratracheally with $F$. novicida or with F. novicida-infected A. castellanii. Surprisingly, infection with F. novicida-infected A. castellanii did not lead to bronchopneumonia in Balb/c mice, and Francisella did not disseminate into the liver and spleen. Upon inhalation, F. novicida infects a variety of host cells, though neutrophils are the predominant cells early during infection in the lung infiltrates of pulmonary tularemia. The numbers of neutrophils in the lungs of Balb/c mice were significantly lower in the infection of mice with $F$. novicida-infected $A$. castellanii in comparison to group of mice infected only with F. novicida. These results demonstrate that following inoculation of mice with F. novicida-infected $A$. castellanii, mice did not develop tularemia.

Keywords: Francisella, amoeba, mice, tularemia, pathogenesis

\section{INTRODUCTION}

Francisella tularensis is a gram negative bacterium and causative agent of zoonotic disease, tularemia. Five species of the genus Francisella has been recognized: F. tularensis, F. philomiragia, F. hispaniensis, F. noatunensis, and F. novicida (Sjödin et al., 2012; Kingry and Petersen, 2014). Tularemia in humans is mostly caused by two subspecies of F. tularensis, tularensis (Type A) and holarctica (Type B). F. novicida U112 is avirulent in immunocompetent humans but is very virulent in experimental mice, only few bacteria cause disease and death, similar to Francisella tularensis subsp. tularensis (Sjödin et al., 2012). The most common way of transmission of the disease is by exposure to infected arthropod vectors, or by handling, ingesting, or inhaling infectious materials. 
Aerosol transmission of $F$. tularensis cause most severe tularemia leading to mortality rates up to $30 \%$ with the F. tularensis subsp. tularensis (Dienst, 1963).

F. tularensis has been found in many animal species, including fish, birds, amphibians, rabbits, squirrels, hares, voles, ticks, and flies (Sjöstedt, 2007; Akimana and Kwaik, 2011). In vitro studies showed that $F$. tularensis can survive and grow within A. castellanii and H. vermiformis cells (El-Etr et al., 2009; Santic et al., 2011) as well as within amoebal cysts (El-Etr et al., 2009). The isolation of $F$. tularensis subsp. holarctica from rivers, lakes, streams and ponds (Willke et al., 2009; Broman et al., 2011) supports the hypothesis that protozoa may serve as a reservoir for F. tularensis in nature (Willke et al., 2009; Broman et al., 2011). Very little is known about the F. tularensis-amoeba interaction. Free-living amoebae such as Acanthamoeba and Hartmannella are environmental hosts of several intracellular pathogens such as Legionella, Chlamydia, and Mycobacterium (Thomas et al., 2008; Jacquier et al., 2013). L. pneumophila is an intracellular gram-negative bacterium, ubiquitous in the aquatic environment and important causative agent of communityacquired and nosocomial bacterial pneumonia. The bacterium enters the human body via inhalation of aerosol droplets. Once in the lungs, L. pneumophila invades and replicate mainly in alveolar macrophages (Richards et al., 2013).The pathogenesis of legionellosis depends also on prior adaptation of L. pneumophila in the natural water environment (Richards et al., 2013). In freshwater, Legionella survive and replicate within free-living protozoa including ciliates Tetrahymena and Cyclidium spp. as well as amoeba species belonging to Acanthamoeba, Hartmanella, Valkampfia, Naegleria, and Dictyostelium (Barbaree et al., 1986; Cianciotto and Fields, 1992; Declerck et al., 2007a,b; Dey et al., 2009; Bozzaro and Eichinger, 2011; Tyson et al., 2014). It has been shown that Legionellae interact with their protozoan hosts and mammalian cells in a similar way (Harb et al., 2000; Brüggemann et al., 2006). The amoeba-grown Legionella were found to enter the macrophages at a higher frequency than agargrown legionela (Cirillo et al., 1994). In addition, it has been shown that growth of L. pneumophila in the lungs of A/J mice is potentiated by L. pneumophila-infected $H$. vermiformis (Brieland et al., 1996). Similarly, A. castellanii-grown L. pneumophila is more infectious than agar grown bacteria (Cirillo et al., 1999). These data show that coincident inhalation of protozoa harboring L. pneumophila enhances the severity of Legionnaire's disease. Our previous results showed a different intracellular lifestyle of F. novicida within $H$. vermiformis in comparison to mammalian cells (Santic et al., 2011). While in mammalian cells cytosolic location of bacteria after escape from the vacuole is a crucial step in productive intracellular replication, in amoeba cells the bacteria are enclosed in the vacuole where they replicate (Abd et al., 2003; Santic et al., 2011).

F. tularensis does not induce a classical pulmonary proinflammatory immune response (Bosio et al., 2007; Chase et al., 2009; Allen, 2013). The flow cytometry analysis of F. tularensis infected mouse lung cells indicates that neutrophils are the predominant infected cells by day 3 after infection (Hall et al., 2008; Allen, 2013). In addition, it has been shown that neutrophils are crucial for early host defense against systemic, but not respiratory LVS (live vaccine strain) F. tularensis infection in mice (Conlan et al., 2002). It seems that macrophages are central to the innate response to infection while neutrophils plays a role through initiating immune cell infiltration (Cowley and Elkins, 2011; Allen, 2013). However, little is known about the role of neutrophils in pathogenesis of the disease.

Tularemia is most deadly in the pneumonic form. After inhalation of contaminated dust, often by farming activities or landscaping respiratory tularemia could occur. During the respiratory form of disease, pneumonia may not always be present but may be present in other forms of tularemia (Santic et al., 2007b; Moskowitz and Wiener-Kronish, 2010). Francisella replicate at the initial site of entry, and then spread to the lymph nodes, liver and spleen (Forestal et al., 2007; Santic et al., 2007b; Sharma et al., 2011). It has been speculated that $F$. tularensis persists in water between tularemia outbreaks (Broman et al., 2011). We have previously demonstrated that $\mathrm{Balb} / \mathrm{c}$ mice develop replicative $F$. novicida lung infection in response to intratracheal inoculation with virulent $F$. novicida, with maximal intrapulmonary growth of $F$. novicida at $72 \mathrm{~h}$ postinoculation (Santic et al., 2007b). In the current study, we tested the hypothesis that, similar to L. pneumophila, inhaled F. tularensis-infected protozoon may constitute an infectious particle for tularemia. We showed the bacterium enclosed in the vacuole of amoeba cells within the lungs. The results demonstrate that infection of $F$. novicida-infected A. castellanii organism does not initiate neither pulmonary nor systemic tularemia in $\mathrm{Balb} / \mathrm{c}$ mice. The recruitment of polymorphonuclear cells is not evident during coinfection of Balb/c mice with $F$. novicidainfected A. castellanii. These results demonstrate that in contrast to L. pneumophila, inhaled protozoa do not serve as a vehicle in the pathogenesis of respiratory murine tularemia caused by F. novicida.

\section{MATERIALS AND METHODS}

\section{Bacteria and Amoeba Cultures}

The wild type F. novicida strain U112 (Fn) and L. pneumophila strain AA100 (Lpn) were grown on buffered-charcoal yeast extract (BCYE) agar plates as have been described previously (Santic et al., 2005b, 2007a). A. castellanii was obtained from the American Type Culture Collection, 30234. The amoebae were grown in medium 30234 at $25^{\circ} \mathrm{C}$, as described elsewhere (Pedersen et al., 2001; El-Etr et al., 2009; Santic et al., 2011). For preparation of the inoculums, $A$. castellanii were collected from the culture flasks, centrifuged (350xg, $30 \mathrm{~min}$ ), resuspended in PBS, counted in hemocytometer (Neubauer chamber), washed once in phosphate-buffered saline (PBS) and suspended in PBS at $10^{5}$ cells per $\mathrm{ml}$.

\section{In vitro Infection Assay}

To examine the virulence of amoeba-grown bacteria in mice, we used L. pneumophila as a control by the methods described previously (Cirillo et al., 1994; Brieland et al., 1997b).

For preparation of $F$. novicida-infected A. castellanii, confluent monolayers of $A$. castellanii were inoculated with 
F. novicida at a multiplicity of infection of 10 for $30 \mathrm{~min}$. After $30 \mathrm{~min}$, the monolayers were washed to remove nonadherent bacteria and incubated in media containing gentamicin (100 $\mu \mathrm{g} / \mathrm{ml}$ ) for $1 \mathrm{~h}$ to kill extracellular bacteria. Antibiotic-containing medium was subsequently removed and replaced with antibioticfree medium, and F. novicida infected-amoeba monolayers were incubated for further $6 \mathrm{~h}$ period, to reach the number of bacterium within the amoeba cells of $10^{4} \mathrm{cfu} / \mathrm{ml}$. One hour prior to harvest, the monolayers were treated again with gentamicin $(100 \mu \mathrm{g} / \mathrm{ml})$. F. novicida-infected amoebae were subsequently removed from the flasks, resuspended in PBS and used in vivo within $30 \mathrm{~min}$ of preparation. To determine the number of bacteria, amoeba was lysed with Triton $\times 100(0.1 \%)$ for $10 \mathrm{~min}$, washed in PBS, measured by spectophotmetry and plated on BCYE agar, respectively. Results of our experiment showed that $F$. novicida replicated in amoeba resulting in number of bacteria $10^{4} \mathrm{cfu} / \mathrm{ml}$ at $6 \mathrm{~h}$ after infection. The in vivo virulence of Francisella after growing in amoeba was determined as well. The $6 \mathrm{~h}$ coculture of $F$. novicida and A. castellanii (MOI 10) was centrifuged for $30 \mathrm{~min}$ at $350 \times$ $\mathrm{g}$ to pellet the bacteria and amoeba. The pellet was suspended in $1 \mathrm{ml}$ of distilled water for $10 \mathrm{~min}$ and passed through a 27-gauge syringe three times to lyse remaining amoebae as described. To remove any remaining amoebae, we centrifuged this preparation for $1 \mathrm{~min}$ at $150 \times \mathrm{g}$ and transferred the supernatant to the new tube. The Francisella $\left(10^{3}\right.$ cfu per mouse) and/or Legionella suspension $\left(10^{5} \mathrm{cfu}\right.$ per mouse) were used in vivo.

\section{Mice Infection}

Female pathogen-free Balb/c and A/J mice, 8-9 weeks of age, were used in all experiments. Mice were housed in specific pathogen free conditions within our animal care facility according to standard guidelines, and the use of animals for infection was approved by the institutional IACUC.

The mice were anesthetized by intraperitoneal (i.p.) injection of ketamine ( $2.5 \mathrm{mg}$ per mouse). The incision was made through the skin of the ventral neck, the trachea was isolated and $50 \mu \mathrm{l}$ of the bacterial suspension in sterile saline was inoculated using a 26-gauge needle followed by $10-20 \mu \mathrm{l}$ of air by intratracheal infection (i.t.). A/J mice were inoculated with L. pneumophila ( $10^{5}$ cfu per mouse) and/or L. pneumophila-infected A. castellanii (MOI $10,10^{6}$ amoebae containing $10^{5}$ bacteria, harvested after $6 \mathrm{~h}$ of coculture). Balb/c mice were inoculated with $F$. novicida ( $10^{3}$ cfu per mouse), A. castellanii $\left(10^{4}\right.$ cells per mouse) and/or with $F$. novicida-infected $A$. castellanii (MOI 10, harvested after $6 \mathrm{~h}$ of coculture). Control animals were inoculated with saline only. The skin incision was surgically closed. At 2, 24, 48, and $72 \mathrm{~h}$ postinoculation, the mice were euthanized, the lung, liver and spleen were removed and homogenized, and F. novicida cfu were determined by culture of tissue homogenates on BCYE agar. The cfu of L. pneumophila were determined in the lung homogenates.

For mortality, 10 mice per group were infected either with $F$. novicida, A. castellanii, and/or F. novicida-infected $A$. castellanii as described above. Mice were observed daily during 15 days period.

\section{Histopathology Studies}

The histological changes in the lungs of Balb/c mice in response to infection were assessed by light microscopy as described previously (Santic et al., 2007b). At 2, 24, 48, and $72 \mathrm{~h}$ after inoculation, the mice were humanely sacrificed. Before organ removal, the pulmonary vasculature was perfused with $10 \mathrm{ml}$ of saline containing $5 \mu \mathrm{M}$ EDTA, via the right ventricle. The excised organs were fixed in $10 \%$ neutral formalin for $24 \mathrm{~h}$, dehydrated and embedded in paraffin. Sections $(5 \mu \mathrm{m})$ were cut, stained with haematoxylin and eosin (H\&E), and analyzed by light microscopy. On average of $100.2 \mu \mathrm{m}$ thick serial sections of each image were captured and stored for further analyses. Twenty random high-powered fields (HPFs) were assessed to grade inflammation severity including alveolar and bronchial damage as well as percentage of parenchyma involved. The histology assessment included the number of the mononuclear cells and percent of parenchyma involved by using modification of double-blind scoring method at a magnification of $40 \mathrm{x}$, as described previously (De Simone et al., 2014).The inflammation process was graded normal (score of 0 ) when there were 0 19 monocular cells infiltrates per HPF with no alveolar and bronchial involvement, mild (score of 1) for 20-49 cells per HPF including mild damage of alveolar and bronchial regions, moderate (score of 2) for 50-99 cells per HPF with moderate alveolar and bronchial inflammation, or severe (score of 3 ) for 100-200 mononuclear cells per HPF with severe effacement of alveolar and bronchial regions. The murine lung section was examined in sagittal direction and percent of parenchyma involved was scored as 0 when no area was compromised. The involvement of the parenchyma was scored as 1 when up to $25 \%$ of the total area was occupied by inflammatory exudate; was scored as 2 when $26-50 \%$ of parenchyma area was occupied with inflammatory cells, 3 if comprised more than $51 \%$. The total histology score was calculated as an average of individual criteria scores. The uninfected tissue was used as a baseline score, ${ }^{*} P<0.05$ and ${ }^{* *} P<0.001$. In addition, statistically significant differences between $F$. novicida and $F$. novicidainfected $A$. castellanii groups are marked by ${ }^{\star} p<0.05$. The bar represents the median score in each group.

\section{Inflammatory Cell Recruitment into the Lung}

Mice were intratracheally inoculated with $F$. novicida, A. castelannii and/or with $F$. novicida-infected A. castellanii. All mice were subsequently processed and analyzed individually. At $24 \mathrm{~h}$ after infection, mice were humanely sacrificed. The lungs were excised, minced, and incubated in RPMI 1640 medium containing $5 \%$ fetal calf serum, $1 \mathrm{mg}$ of collagenase A (Sigma Chemical Company, St. Louis, Mo) per ml, and $20 \mu \mathrm{l}$ DNase per ml (Sigma Chemical Company, St. Louis, Mo.) for $60 \mathrm{~min}$ at $37^{\circ} \mathrm{C}$ in shaking incubator. The cells were further disaggregated by drawing the lung homogenate repeatedly through a 10-ml syringe 20-30 times prior to pelleting of the cells by centrifugation. Cells were isolated using Percoll (Fluka) gradient. Isolated cells were resuspended in PBS supplemented with $2 \%$ FCS and $0.03 \% \mathrm{NaN}_{3}$ and blocked with 
purified rat anti-mouse CD16/CD32 (BD Pharmingen). The cells were phenotyped using monoclonal antibodies specific for the following leukocyte surface antigens: anti-CD11b (BD Pharmingen) and anti-GR-1 (Miltenyi Biotec). Lymphocyte and macrophages were gated according to their size and granularity defined in the forward light scatter (FSC) and side light scatter (SSC) plot. Neutrophils were gated as CD11b ${ }^{+}$and GR-1 $1^{+}$cells while mononuclear cells were gated as $\mathrm{CD} 11 \mathrm{~b}^{+}$and GR-1 ${ }^{-}$cells. The immunofluorescence analysis was performed by BD FACS Calibur $^{\mathrm{TM}}$ flow cytometer using CellQuest ${ }^{\mathrm{TM}}$ software.

\section{Electron Microscopy}

For electron microscopy, at 2 and $24 \mathrm{~h}$ after infection lung tissues of Balb/c mice were removed and fixed in 2.5\% gluteraldehyde (infection procedure is described above). Briefly, lungs were post fixed by immersion in $2 \%$ osmium tetroxide in $0.1 \mathrm{M}$ sodium Sorenson's buffer for $1 \mathrm{~h}$, followed by dehydration in acetone, infiltration and embedding in Epon 12 epoxy resin. Sections $(0.5 \mu \mathrm{m})$ were stained with toluidine blue and scanned by light microscopy to define areas containing bacteria for ultrastructural examination. Ultrathin sections $(0.1 \mu \mathrm{m})$ were then cut, stained with uranyl acetate and lead citrate, and examined in Philips transmission electron. The integrity of phagosomal membrane was determined by electron microscopy counting at least 100 bacteria for each sample and using following criteria: (a) cytosolic localization of bacteria, (b) vacuolar localization of bacteriaintact vacuoles.

\section{Statistics}

Statistical analyses were performed with GraphPad Prizm version 6.0 software. Bacterial burdens, cell populations and histopathology scoring were compared by $t$-test. Survival curves were compared by the log-rank Mantel-Cox test. ${ }^{*} P<0.05$ and ${ }^{* *} P<0.001$ were accepted as significantly different.

\section{Ethics Statement}

All the experimental procedures were in compliance with National guidelines and were approved by the Institutional Animal Care and Use committee (IACUC) at Faculty of Medicine, University of Rijeka.

\section{RESULTS}

\section{The Survival and Growth of $F$. novicida in the Organs of Balb/c Mice Inoculated with F. novicida-Infected $A$. castellanii}

It has been shown that $F$. novicida replicates in different phagocytic and non phagocytic cells. Our and other studies have shown that $F$. tularensis subsp. holarctica, tularensis, and $F$. novicida survive and replicate in $A$. castellanii while $F$. novicida is able to replicate in $H$. vermiformis as well (Abd et al., 2003; El-Etr et al., 2009; Santic et al., 2011). F. novicida, although avirulent for humans, is highly virulent in $\mathrm{Balb} / \mathrm{c}$ and $\mathrm{C} 57 \mathrm{Bl} / 6$ mice causing severe tularemia (Kieffer et al., 2003; Lauriano et al., 2004; Pammit et al., 2004; Shen et al., 2004; Mares et al., 2010). The severity of the disease is dependent on bacterial strain and the route of infection (Conlan et al., 2011). Our previous results showed that the dissemination of Francisella in Balb/c mice following intratracheal infection with the wild-type strain of $F$. novicida is similar to that previously reported for intranasal or aerosol infection (Santic et al., 2007b).

We used previously established murine model of L. pneumophila-infected amoeba as control for this study (Cirillo et al., 1994; Brieland et al., 1997b). A/J mice were inoculated with $L$. pneumophila ( $10^{5} \mathrm{cfu}$ per mouse) and/or L. pneumophila-infected A. castellanii (MOI 10, $10^{6}$ amoebae containing $10^{5}$ bacteria, harvested after $6 \mathrm{~h}$ of coculture). Consistent with previous studies, L. pneumophila replicated more robustly in the lungs of mice that were infected with L. pneumophila-infected A. castellani (Figure 1A). In contrast, intrapulmonary growth of $L$. pneumophila was significantly lower in A/J mice inoculated with L. pneumophila alone (Figure 1A) $(t$-test, $p<0.05)$.

$\mathrm{Balb} / \mathrm{c}$ mice were inoculated intratracheally with $F$. novicida $\left(10^{3}\right.$ bacteria per mouse), A. castellani $\left(10^{4}\right.$ cells per mouse $)$ and/or F. novicida-infected A. castellanii $\left(10^{3}\right.$ bacteria per mouse in $10^{4}$ cells per mouse- determined after $6 \mathrm{~h}$ culture). We also compared the virulence of intracellular $F$. novicida grown in amoeba for $6 \mathrm{~h}$. The amoeba were lysed, and $10^{3}$ of purified intracellular F. novicida were inoculated intratracheally in the $\mathrm{Balb} / \mathrm{c}$ mice. As a control one group of mice were infected with A. castellanii alone ( $10^{4}$ cells per mouse).

At $2,24,48$, and $72 \mathrm{~h}$ postinoculation, the mice were euthanized, the lungs, liver and spleen were excised and homogenized, and the numbers of $F$. novicida cfu per organs homogenate were compared. Our results showed that when mice were inoculated with $F$. novicida alone, bacteria proliferated robustly in the lungs of mice with the peak of infection at 48 and $72 \mathrm{~h}$, where the number of bacteria reached almost $10^{9} \mathrm{cfu}$ (Figure 1B). In contrast the number of bacteria in the lungs of F. novicida-infected A. castellani mice reached only around $10^{4}$ cfu at $48 \mathrm{~h}$ after infection ( $t$-test, $p<0.05)$ (Figure 1B). At all time points examined there was a significant difference ( $t$-test, $p$ $<0.05$ ) in the cfu of bacteria in the lungs of infected mice between these two experimental groups (Figure 1B). In the group of mice infected with purified $F$. novicida after growing in amoeba cells for $6 \mathrm{~h}$ we did not find any differences in intracellular replication of bacteria in lungs of mice compared to mice infected with BCYE-grown $F$. novicida (Figure 1B; $t$-test, $p$ was 0.05 ).

The dissemination of $F$. novicida to the liver and spleen after infection $F$. novicida-infected $A$. castellanii was also assessed. In the group of mice infected with $F$. novicida alone the number of bacteria that reached the spleen and liver were up to $10^{6} \mathrm{cfu} /$ $\mathrm{ml}$ at $72 \mathrm{~h}$ after infection (Figures 1C,D). In contrast, only 10 bacteria reached the liver and spleen after infection of mice with F. novicida-infected A. castellani (Figures 1C,D; $t$-test, $p<0.05$ ).

\section{The Francisella-Amoeba Coinfection Do Not Enhance the Mortality of Mice}

There is little differences in susceptibility to tularemia infections depending on mice strain (Fritz et al., 2014) but Balb/c mice were most commonly used in experimental tularemia. We infected $\mathrm{Balb} / \mathrm{c}$ mice intratracheally with $F$. novicida, A. castellanii, and/or F. novicida-infected A. castellanii. The dose of $1 \times 10^{3} \mathrm{cfu}$ per mouse was used for infection with $F$. novicida which is sufficient 
A

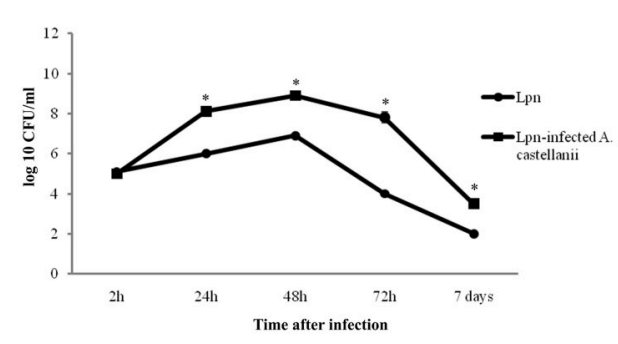

C

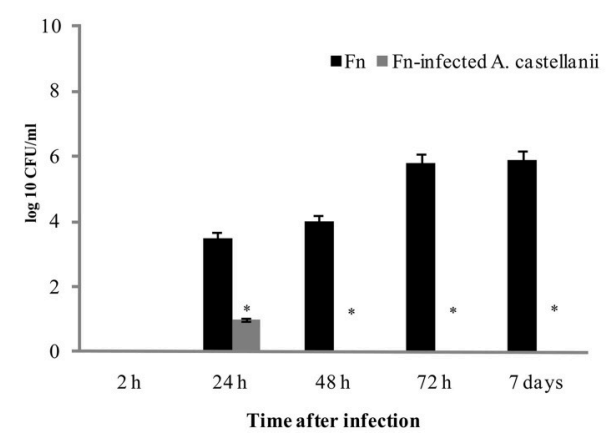

B

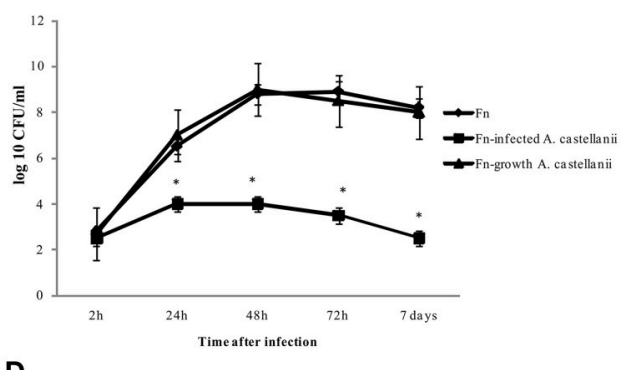

D

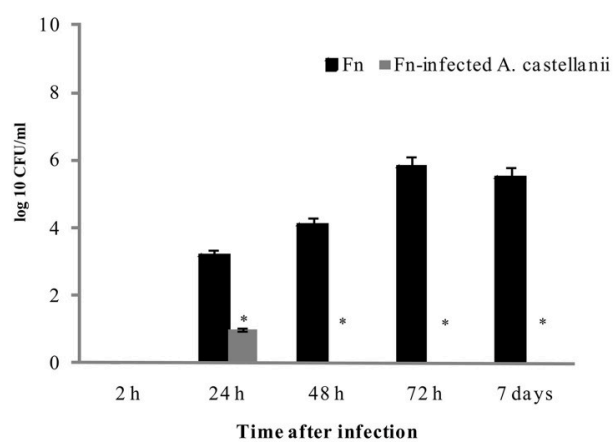

FIGURE 1 | Growth kinetics of L. pneumophila and L. pneumophila-infected A. castellanii in lungs of A/J mice (A); F. novicida and F. novicida-infected A. castellanii in lungs (B), liver (C), and spleen (D) of Balb/c mice. At different time points after intratracheal infection of mice, organs were removed for determination of the number of bacteria (cfu) by plating serial dilutions on agar plates. The error bars represent standard deviations of triplicate samples and the results shown are representative of three independent experiments, ${ }^{*} p<0.05$.

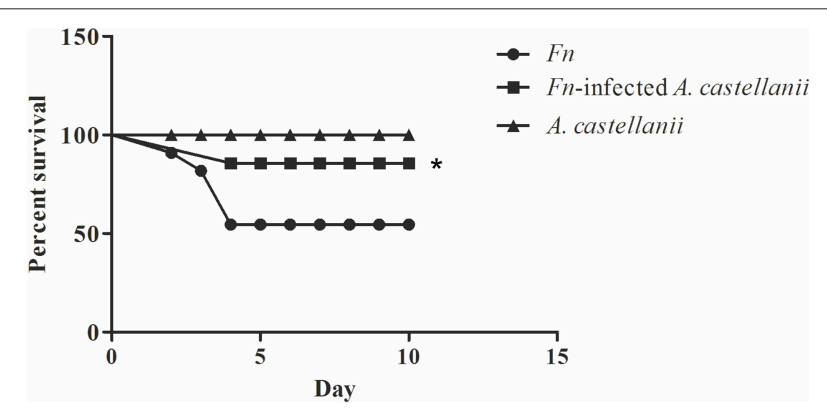

FIGURE 2 | Survival of Balb/c mice. Balb/c mice inoculated intratracheally with F. novicida, A. castellanii, and/or F. novicida-infected A. castellanii were observed twice daily for 15 days for clinical signs of illness or survival. Results represent combined results of two separate experiments and 10 animals per treatment group, ${ }^{\star} p<0.05$.

to cause mortality in $50 \%$ of mice. After the infection, mice were observed during 15 days (Figure 2).

We observed that mice infected with $F$. novicida exhibited clinical signs of infection. Symptoms persisted and worsened, and $40 \%$ of mice died between 3 and 4 days post infection with F. novicida (Figure 2).

The symptoms of the disease in the group of F. novicidainfected $A$. castellanii mice were much milder compared the group of mice infected with $F$. novicida alone. In this group of mice, $90 \%$ of mice survived the infection (Figure 2) (MantelCox-test, $p<0.05$ ).
The group of mice infected with $A$. castellanii alone did not show any symptoms of the disease and this group were similar to uninfected mice. The infected Balb/c mice were quite active at the all time points observed (Figure 2).

\section{Pulmonary Pathology}

At the early time points of $2 \mathrm{~h}$ post infection in all examined groups the lungs of mice exhibited minor differences in terms of the cellular constituency (Figures 3A,B; $t$-test, $p>0.05$ ). At $24 \mathrm{~h}$ after infection in the lungs of Balb/c mice infected only with $A$. castellanii, several mononuclear cells were present in peribronchial areas (Figures 3A,B). This cell type was generally absent from the lungs of uninfected mice even though was not statistically significant (Figures 3A,B; $t$-test, $p>0.05$ ). At $24 \mathrm{~h}$ after infection with $F$. novicida, the pathological changes of the bronchiolar cells were characterized by a vacuolar degeneration (Figure 3A). The peribronchiolar spaces were infiltrated with mononuclear cells (Figure 3B; $t$-test, $p<0.001$ ). The infiltration was also observed within bronchiole and alveoli but with less intensity than in peribronchiolar spaces (Figure 3A). In the group of mice inoculated with $F$. novicida-infected $A$. castellanii the infiltration process in pervivascular and peribronchial areas was present but with less extent then from the group of mice infected with $F$. novicida only (Figures 3A,B; $t$-test, $p<0.05$ ).

At 48 and $72 \mathrm{~h}$ after infection the histopathological changes in the lung tissues of Balb/c mice infected with $A$. castellanii alone were minor (Figures 3A,B; $t$-test, $p>0.05$ ). Some thickness of peribronchial walls was observed but was notably 


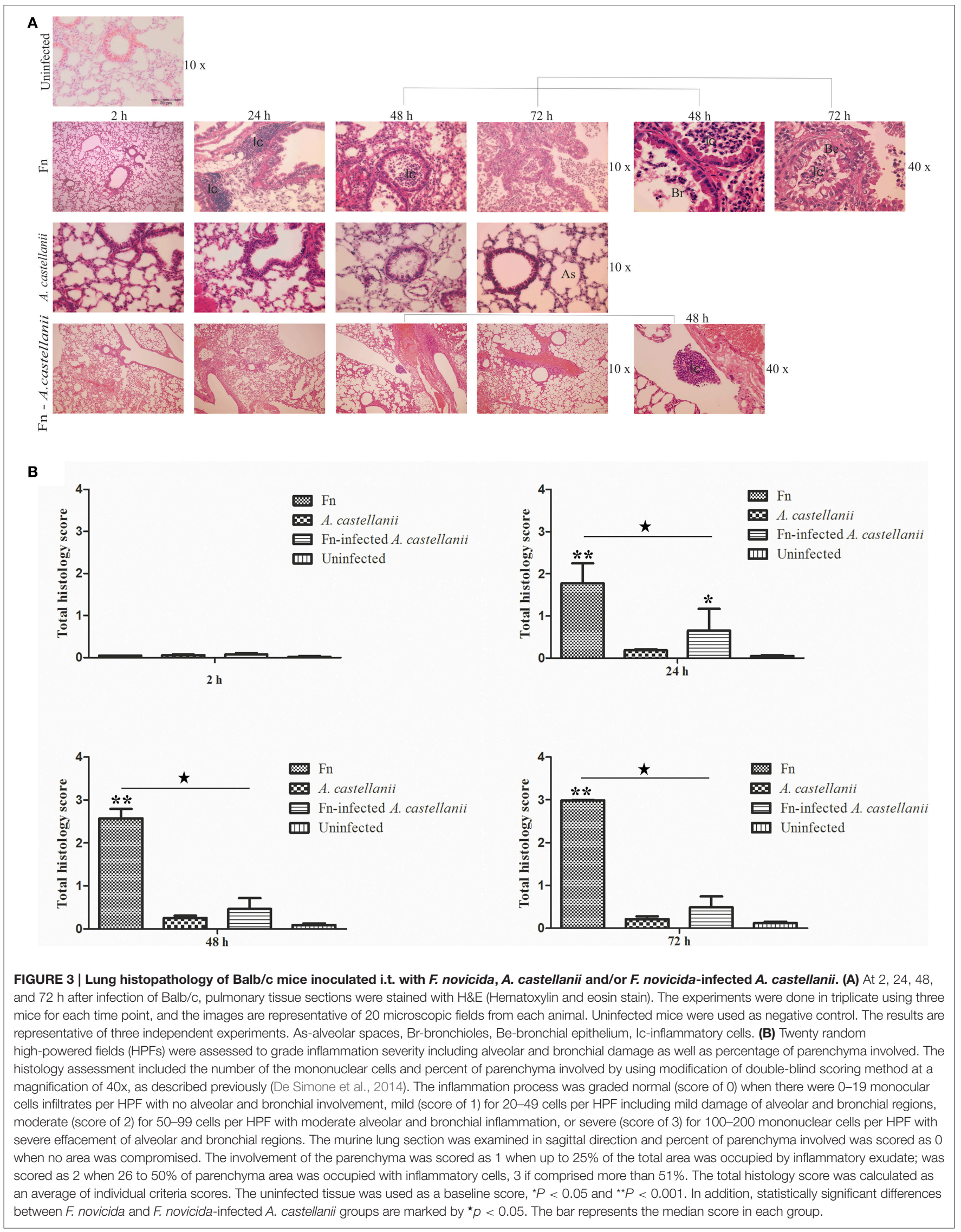


present in uninfected mice as well (Figure 3A). However, at $48 \mathrm{~h}$ after infection with $\mathrm{F}$. novicida, in the lungs of Balb/c mice bronchopneumonia were present (Figure 3A). There were high numbers of inflammatory cells in the lumen of bronchia (Figures 3A,B; $t$-test, $p<0.001$ ). The tissue surrounding the blood vessels were damaged and fibrinous exudates were present in alveolar spaces (Figure 3A). The histopatology changes at $72 \mathrm{~h}$ post infection with $F$. novicida alone were similar to those at $48 \mathrm{~h}$ after infection (Figure 3A). Surprisingly, the group of mice infected with $F$. novicida-infected $A$. castellanii, showed no signs of pulmonary pathology neither at 48 nor at $72 \mathrm{~h}$ of infection. The histopathology of these group of mice showed similar symptoms as group of mice infected with $A$. castellanii alone or the group of uninfected mice (Figures 3A,B; $t$-test, $p>0.05$ ). The significant difference in overall histopathology score was found between group of mice infected with only $F$. novicida and $F$. novicidainfected $A$. castellanii mice (Figure 3B). Our results show that infection of mice with $F$. novicida-infected $A$. castellanii does not enhance the pulmonary pathology of mice.

\section{Inoculation of Mice with $F$. novicida-Infected $A$. castellanii Blocks the Recruitment of Neuthrophils into Mice \\ Lungs}

It has been shown that neutophils are one of the first cell to be recruited in Francisella lung infection (Cowley and Elkins, 2011). We determined how Francisella infections impacted mononuclear and polymorphonuclear (PMN) cells populations in the lungs at $24 \mathrm{~h}$ after infection. We compared the influx of PMN cells, neutrophils, in the lung tissues of mice infected with $F$. novicida-infected $A$. castellanii in comparison to the lung tissues of mice infected with $F$. novicida and/or A. castellanii by flow cytometry.
Lungs from mice infected with $F$. novicida, A. castellani and/or F. novicida-infected $A$. castellanii had more $\mathrm{CD}_{11} \mathrm{~b}^{+} \mathrm{Gr}^{-}$ lung tissue macrophages then the lung of uninfected mice ( $t$-test, $p<0.05$; Figure 4A). Considering that mononuclear cells populations $\left(\mathrm{CD} 11 \mathrm{~b}^{+} \mathrm{Gr}^{-}\right)$are very low at the day 1 after infection, it is possible that there is a balance between macrophage recruitment to the lung and macrophage killing.

A significant increase in the percentage of neutrophils $\left(\mathrm{CD} 11 \mathrm{~b}^{+} \mathrm{Gr}^{+}\right.$cells) was evident at $24 \mathrm{~h}$ post infection in the lungs of mice infected only with $F$. novicida in comparison to uninfected mice ( $t$-test, $p<0.05$; Figure 4B). Consistent with previous data from this study there was no significant change in the percentage of $\mathrm{CD}_{11} \mathrm{~b}^{+} \mathrm{Gr}^{+}$cells from F. novicidainfected A. castellanii mice compared to PBS control mice at $24 \mathrm{~h}$ after infection ( $t$-test, $p=0.123)$. However, there is significant difference in percentage of neutrophils between the groups of mice infected with $F$. novicida and the group of mice coinfected with $F$. novicida-infected $A$. castellanii ( $t$-test, $p<$ $0.05)$. The percentage of neutrophils was slightly increased but not significantly in the groups of mice infected with $A$. castellanii in comparison to the group of uninfected mice ( $t$-test, $p=0.087$ ). There was no significant recruitment of neutrophils in the lungs of mice coinfected with $F$. novicida-infected A. castellanii.

\section{Vacuolar Localization of Bacteria in Lung Tissues of $F$. novicida-Infected}

\section{A. castellanii}

It has been shown that the prior to bacterial escape into the cytosol of macrophages, where bacterial proliferation occurs, Francisella-containing vacuole (FCV) matures to a late endosome-like phagosome (Clemens et al., 2004; Santic et al., 2005a, 2008; Chong et al., 2008; Bröms et al., 2010; Asare and Kwaik, 2011). In mammalian cells the process of phagosomal
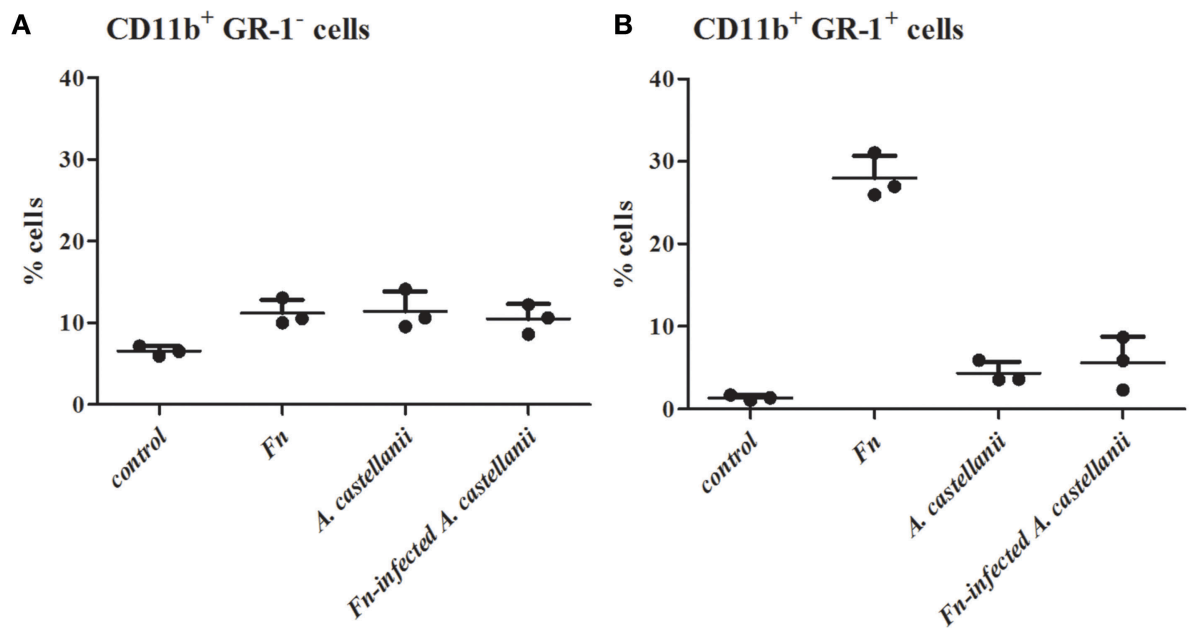

FIGURE 4 | Effect of $F$. novicida-infected $A$. castellanii on lung tissue macrophages (MNC, CD11b+ GR-1-) (A) and neutrophils (PMN, CD11b+ GR-1+) (B) cell recruitment into the lungs of Balb/c mice. Balb/c mice were inoculated intratracheally with F. novicida, $A$. castellanii and/or $F$. novicida-infecetd $A$. castellanii. Uninfected mice were used as negative control. At $24 \mathrm{~h}$ after infection mice were sacrificed and inflammatory cell recruitment into the lungs was analyzed. Results represent the mean \pm standard error of the mean of three animals per treatment group. Statistically significant differences between $F$. novicida and F. novicida-infected $A$. castellanii groups are marked by asterisk. ${ }^{*} p<0.05$. 
disruption occurs within 30 min of infection (Golovliov et al., 2003; Checroun et al., 2006; Santic et al., 2010). In contrast, our previous in vitro studies showed that $F$. novicida does not escape from the vacuole in amoeba cells. The bacterium is enclosed within intact vacuole where it replicates (Santic et al., 2011). Based on the above findings we determined localization of the bacterium when inoculated with $F$. novicida-infected A. castellanii in the lung tissues of Balb/c mice.

At $2 \mathrm{~h}$ after infection by $F$. novicida, the bacteria were present in the cytosol within alveolar macrophages in the lung tissues of Balb/c mice (Figures 5A,B). Only $10 \%$ of $F$. novicida were enclosed in intact vacuoles of infected alveolar macrophages in the lung tissue of Balb/c mice. In the lung tissue of mice infected with $F$. novicida-infected $A$. castellanii it was difficult to distinguish between alveolar macrophages and $A$. castellanii cells. The differences are determined based on ultrastrusture of the cells. In the group of $F$. novicidainfected A.castellanii mice, the bacteria were localized mainly within amoeba cells digested by macrophages. In this double phagocytosis $80 \%$ of bacteria were within membrane bound vacuoles at $2 \mathrm{~h}$ after infection ( $t$-test, $p<0.05$; Figures 5A,B). The bacterium was also observed in the amoeba cells alone, and in the alveolar macrophages. Interestingly, when the bacteria were found in macrophage cells they were in the cytosol. In contrast, when the bacteria were found in the amoeba cells within the lung tissue they were found in vacuoles.

By $24 \mathrm{~h}$ after infection, the bacteria were replicating in alveolar macrophages of Balb/c mice. Around $8 \%$ of replicating $F$. novicida were localized in intact vacuoles (Figures $5 \mathbf{A}, \mathbf{B}$ ). In the experimental mice group of $F$. novicida-infected $A$. castellanii, the bacteria were localized in the vacuoles within amoebal cells in the lungs of $\mathrm{Balb} / \mathrm{c}$ mice. Around $80 \%$ of $A$. castellanii harboring the bacteria had intact Francisella-containing vacuoles, in comparison to alveolar macrophages where bacteria were replicating in the cytosol ( $t$-test, $p<0.05$; Figures 5A,B).

\section{DISCUSSION}

Epidemiology of tularemia in some parts of the world, such as Sweden and Turkey, is associated with water-borne transmission, including mosquitoes and amoebae as the potential host reservoirs of the Francisella in water environment (Dai et al., 2010; Zogaj and Klose, 2010; Akimana and Kwaik, 2011; Asare and Kwaik, 2011; Broman et al., 2011; Gavrilin and Wewers, 2011; Jones et al., 2011; Simsek et al., 2012). It has been demonstrated that $F$. novicida and F. philomiragia can structure the biofilm in vitro (Durham-Colleran et al., 2010; Verhoeven
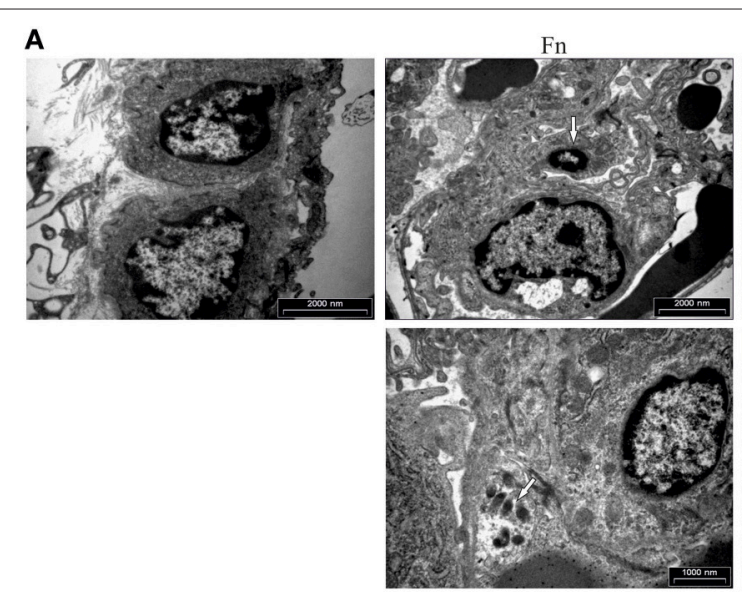

B

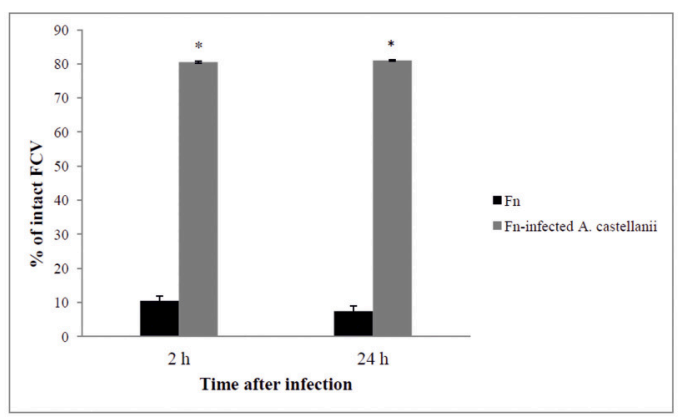

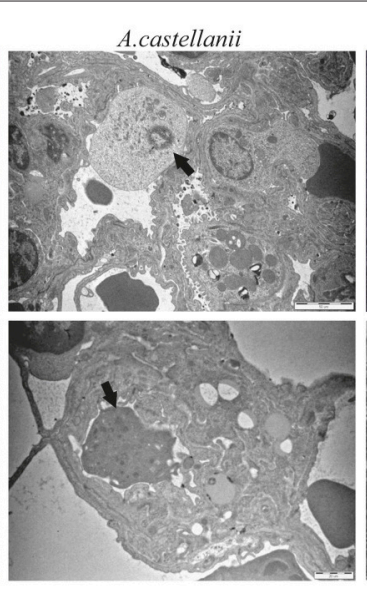

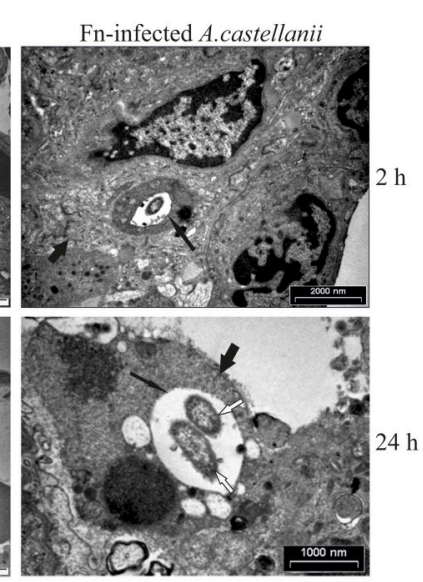

FIGURE 5 | Transmission electron micrographs of pulmonary tissues of Balb/c mice. (A) At 2 and $24 \mathrm{~h}$ after infection of mice with F. novicida, A. castellanii and/or F. novicida-infected A. castellanii lungs were excised, fixed with glutaraldehyde and processed to electron microscopy. Uninfected mice were used as negative control. Thin black arrows show intact vacuolar membranes, tick black arrow show amoeba and white arrows show bacteria. (B) Quantitative analyses of the intact FCV (Francisella containing vacuole). The integrity of phagosomal membrane was determined by electron microscopy counting at least 100 bacteria for each sample and using following criteria: (a) cytosolic localization of bacteria, (b) vacuolar localization of bacteria- intact vacuoles. ${ }^{*} p<0.05$. 
et al., 2010). It has been hypothesized that F. novicida and LVS utilize A. castellanii as a natural reservoir (Abd et al., 2003; El-Etr et al., 2009; Santic et al., 2011). In addition, virulent strains of $F$. tularensis survive for weeks within A. castellanii (Abd et al., 2003; El-Etr et al., 2009).

Previous studies showed that amoeba-grown L. pneumophilla exhibited an increased capacity to enter tissue culture cells compared to agar-grown bacteria (Cirillo et al., 1994) and to be more infectious for mice (Cirillo et al., 1999). These results lead to the hypothesis that L. pneumophila that have been grown intracellulary in amoebae may be more infectious. In vivo studies have shown that as few as one inhaled or aspirated L. pneumophila-infected amoeba may constitute an infectious particle for Legionnaires' disease (Brieland et al., 1997a). In the environment, protozoa maintain L. pneumophila in natural aquatic and potable water systems, as they both provide a niche for bacterial replication and serve as a vehicle to protect L. pneumophila during the process of water treatment. We and others have previously demonstrated that $\mathrm{Balb} / \mathrm{c}$ mice develop replicative $F$. novicida lung infection in response to intratracheal inoculation with virulent F. novicida cells (Santic et al., 2007b; Yu et al., 2008; Signarovitz et al., 2012). There is one study that shows BHI-grown Francisella cells closely mimic their hostadapted counterparts which have emerged from macrophages (Hazlett et al., 2008). The experiments conducted in parallel with BHI- or macrophage-grown F. tularensis cells indicate that these host-adapted bacteria induce very low levels of MAP kinase activity and stimulate little or no secretion of proinflammatory cytokines (Hazlett et al., 2008). It is not known whether inhalation of F. novicida-containing aerosols or microaspiration of contaminated water with amoeba could cause and enhance the disease, similar to L. pneumophila (Brieland et al., 1997a).

Results from this study shows that $F$. novicida-infected A. castellanii organisms do not induce a severe form of tularemia in Balb/c mice. In addition, $F$. novicida infected $A$. castellanii is even less pathogenic for mice than F. novicida alone. The intrapulmonary growth of $F$. novicida was significantly greater in mice inoculated with $F$. novicida alone compared to mice inoculated with $F$. novicida-infected $A$. castellanii, where there is inhibition of the bacterial growth. In addition, in contrast to systemic infection caused by infection of mice with F. novicida alone there was no such high dissemination of bacterium in the liver and spleen when mice were infected with $F$. novicida -infected $A$. castellanii. These findings are in contrast to L. pneumophila infections where L. pneumophila inhaled protozoa act as cofactors that enhance pathogenesis of Legionnaires' disease (Brieland et al., 1997a). It is possible that infection of alveolar macrophages during Legionnaires' disease imitate the intracellular infection of protozoa by L. pneumophila. The life style of $F$. novicida is very different in amoeba cells in comparison to mammalian cells, where cytoplasmic location of bacteria is crucial step in productive intracellular replication (Santic et al., 2011). In protozoa Francisella do not escape from the vacuole into the cytoplasm, but remain enclosed in vacuoles (Santic et al., 2011). It is possible that F. novicida is trapped within amoeba and the productive infection is not developed in vivo. This is consistent with a clinical study conducted in
Sweden where water sampled in Ljusdal during 2004 contained high number of $F$. tularensis subsp. holarctica even though no human cases were recorded in the area (Broman et al., 2011).

Neutrophils are the important cells in controlling bacterial infections with a significant increased phagocytosis relative to macrophages (Kumar and Sharma, 2010). It has been shown that LVS strain of Francisella is quickly taken up by neutrophils, but the respiratory burst is prevented due to disruption of NADPH oxidase assembly within the phagosome (Allen and McCaffrey, 2007; Allen, 2013). In addition, recruitment of neutrophils and monocyte occurred in response to Francisella pulmonary infection, although these cells contribute to the progression of the disease by becoming host cells for Francisella replication (Hall et al., 2008). In contrast, inhalation of F. novicida did not lead to recruitment of neutrophils in the lungs after $4 \mathrm{~h}$ (Hajjar et al., 2006). Because F. novicida-infected A. castellanii did not potentiate intrapulmonary growth of $F$. novicida within $48 \mathrm{~h}$ postinoculation, we investigated the recruitment of inflammatory cells in the lung of infected Balb/c mice. Our results showed that the percentage of lung tissue macrophages were similarly present in mice inoculated with $F$. novicida-infected $A$. castellanii or inoculated with an equivalent number of bacteria. This suggests a proinflammatory effect of $A$. castellanii that is not related to $F$. novicida replication. In contrast, the percentage of neutrophil populations was much higher in the lungs of Balb/c mice being infected with $F$. novicida alone in comparison to $F$. novicidainfected A. castellanii and/or A. castellanii alone. In addition to neutrophil recruitment, we also observed a lower percentage of tissue macrophages in F. novicida-infected mouse lungs. There is speculation that $F$. novicida utilize neutrophils for replication more rapidly than they are being recruited to the site of infection. It is possible that the intravacuolar bacteria cannot stimulate macrophage, and thus do not trigger synthesis and secretion of cytokines that recruit neutrophils to the lungs during F. novicidainfected $A$. castellanii. It is possible that intravacuolar bacteria may block the immune response to recruit neutrophils to the lungs during $F$. novicida-infected $A$. castellanii infection.

In summary, our results demonstrate that in contrast to amoeba-infected by L. pneumophila, F. novicida-infected amoebae are not infectious particles in a murine model of tularemia and perhaps may not enhance bacterial virulence to humans.

\section{AUTHOR CONTRIBUTIONS}

$\mathrm{MO}, \mathrm{MB}$, and $\mathrm{MS}$ contributed in vivo experiment and writing. IG and ZT participated in immunology part of experiment and writing. YA and VM participated in an in vitro experiment and writing.

\section{FUNDING}

This work is supported by a University Grants (Grant No. 13.06.1.1.11 and 13.06.2.2.60). YA is supported by Public Health Service Award 1R01AI120244 and R21AI116517 from the National Institute of Health and by the Commonwealth of Kentucky Research Challenge Trust Fund. 


\section{REFERENCES}

Abd, H., Johansson, T., Golovliov, I., Sandström, G., and Forsman, M. (2003). Survival and growth of Francisella tularensis in Acanthamoeba castellanii. Appl. Environ. Microbiol. 69, 600-606. doi: 10.1128/AEM.69.1.600-606.2003

Akimana, C., and Kwaik, Y. A. (2011). Francisella-arthropod vector interaction and its role in patho-adaptation to infect mammals. Front. Microbiol. 2:34. doi: 10.3389/fmicb.2011.00034

Allen, L. A. (2013). Neutrophils: potential therapeutic targets in tularemia? Front. Cell. Infect. Microbiol. 3:109. doi: 10.3389/fcimb.2013.00109

Allen, L. A., and McCaffrey, R. L. (2007). To activate or not to activate: distinct strategies used by Helicobacter pylori and Francisella tularensis to modulate the NADPH oxidase and survive in human neutrophils. Immunol. Rev. 219, 103-117. doi: 10.1111/j.1600-065X.2007.00544.x

Asare, R., and Kwaik, Y. A. (2011). Exploitation of host cell biology and evasion of immunity by Francisella tularensis. Front. Microbiol. 1:145. doi: 10.3389/fmicb.2010.00145

Barbaree, J. M., Fields, B. S., Feeley, J. C., Gorman, G. W., and Martin, W. T. (1986). Isolation of protozoa from water associated with a legionellosis outbreak and demonstration of intracellular multiplication of Legionella pneumophila. Appl. Environ. Microbiol. 51, 422-424.

Bosio, C. M., Bielefeldt-Ohmann, H., and Belisle, J. T. (2007). Active suppression of the pulmonary immune response by Francisella tularensis Schu4. J. Immunol. 178, 4538-4547. doi: 10.4049/jimmunol.178.7.4538

Bozzaro, S., and Eichinger, L. (2011). The professional phagocyte Dictyostelium discoideum as a model host for bacterial pathogens. Curr. Drug Targets 12, 942-954. doi: 10.2174/138945011795677782

Brieland, J. K., Fantone, J. C., Remick, D. G., Legendre, M., Mcclain, M., and Engleberg, N. C. (1997a). The role of Legionella pneumophila-infected Hartmanella vermiformis as an infectious particle in a murine model of Legionnaires' disease. Infect. Immun. 65, 4892-4896.

Brieland, J. K., Fantone, J. C., Remick, D. G., Legendre, M., Mcclain, M., and Engleberg, N. C. (1997b). The role of Legionella pneumophila-infected Hartmannella vermiformis as an infectious particle in a murine model of Legionnaire's disease. Infect. Immun. 65, 5330-5333.

Brieland, J., Mcclain, M., Heath, L., Chrisp, C., Huffnagle, G., Legendre, M., et al. (1996). Coinoculation with Hartmannella vermiformis enhances replicative Legionella pneumophila lung infection in a murine model of Legionnaires' disease. Infect. Immun. 64, 2449-2456.

Broman, T., Thelaus, J., Andersson, A. C., Bäckman, S., Wikström, P., Larsson, E., et al. (2011). Molecular detection of persistent Francisella tularensis Subspecies holarctica in natural waters. Int. J. Microbiol. 2011:851946. doi: $10.1155 / 2011 / 851946$

Bröms, J. E., Sjöstedt, A., and Lavander, M. (2010). The role of the Francisella tularensis pathogenicity island in Type VI secretion, intracellular survival, and modulation of host cell signaling. Front. Microbiol. 1:136. doi: 10.3389/fmicb. 2010.00136

Brüggemann, H., Cazalet, C., and Buchrieser, C. (2006). Adaptation of Legionella pneumophila to the host environment: role of protein secretion, effectors and eukaryotic-like proteins. Curr. Opin. Microbiol. 9, 86-94. doi: 10.1016/j.mib.2005.12.009

Chase, J. C., Celli, J., and Bosio, C. M. (2009). Direct and indirect impairment of human dendritic cell function by virulent Francisella tularensis Schu S4. Infect. Immun. 77, 180-195. doi: 10.1128/IAI.00879-08

Checroun, C., Wehrly, T. D., Fischer, E. R., Hayes, S. F., and Celli, J. (2006). Autophagy-mediated reentry of Francisella tularensis into the endocytic compartment after cytoplasmic replication. Proc. Natl. Acad. Sci. U.S.A. 103, 14578-14583. doi: 10.1073/pnas.0601838103

Chong, A., Wehrly, T. D., Nair, V., Fischer, E. R., Barker, J. R., Klose, K. E., et al. (2008). The early phagosomal stage of Francisella tularensis determines optimal phagosomal escape and Francisella pathogenicity island protein expression. Infect. Immun. 76, 5488-5499. doi: 10.1128/IAI.00682-08

Cianciotto, N. P., and Fields, B. S. (1992). Legionella pneumophila mip gene potentiates intracellular infection of protozoa and human macrophages. Proc. Natl. Acad. Sci. U.S.A. 89, 5188-5191. doi: 10.1073/pnas.89. 11.5188

Cirillo, J. D., Cirillo, S. L., Yan, L., Bermudez, L. E., Falkow, S., and Tompkins, L. S. (1999). Intracellular growth in Acanthamoeba castellanii affects monocyte entry mechanisms and enhances virulence of Legionella pneumophila. Infect. Immun. 67, 4427-4434.

Cirillo, J. D., Falkow, S., and Tompkins, L. S. (1994). Growth of Legionella pneumophila in Acanthamoeba castellanii enhances invasion. Infect. Immun. $62,3254-3261$.

Clemens, D. L., Lee, B. Y., and Horwitz, M. A. (2004). Virulent and avirulent strains of Francisella tularensis prevent acidification and maturation of their phagosomes and escape into the cytoplasm in human macrophages. Infect. Immun. 72, 3204-3217. doi: 10.1128/IAI.72.6.3204-3217.2004

Conlan, J. W., Chen, W., Bosio, C. M., Cowley, S. C., and Elkins, K. L. (2011). Infection of mice with Francisella as an immunological model. Curr. Protoc. Immunol. Chapter 19, Unit 19. 14. doi: 10.1002/0471142735.im1914s93

Conlan, J. W., KuoLee, R., Shen, H., and Webb, A. (2002). Different host defences are required to protect mice from primary systemic vs pulmonary infection with the facultative intracellular bacterial pathogen, Francisella tularensis LVS. Microb. Pathog. 32, 127-134. doi: 10.1006/mpat.2001.0489

Cowley, S. C., and Elkins, K. L. (2011). Immunity to Francisella. Front. Microbiol. 2:26. doi: $10.3389 /$ fmicb. 2011.00026

Dai, S., Mohapatra, N. P., Schlesinger, L. S., and Gunn, J. S. (2010). Regulation of Francisella tularensis virulence. Front. Microbiol. 1:144. doi: 10.3389/fmicb.2010.00144

Declerck, P., Behets, J., De Keersmaecker, B., and Ollevier, F. (2007a). Receptormediated uptake of Legionella pneumophila by Acanthamoeba castellanii and Naegleria lovaniensis. J. Appl. Microbiol. 103, 2697-2703. doi: 10.1111/j.13652672.2007.03530.x

Declerck, P., Behets, J., Van Hoef, V., and Ollevier, F. (2007b). Detection of Legionella spp. and some of their amoeba hosts in floating biofilms from anthropogenic and natural aquatic environments. Water Res. 41, 3159-3167. doi: 10.1016/j.watres.2007.04.011

De Simone, M., Spagnuolo, L., Lorè, N. I., Rossi, G., Cigana, C., De Fino, I., et al. (2014). Host genetic background influences the response to the opportunistic Pseudomonas aeruginosa infection altering cell-mediated immunity and bacterial replication. PLoS ONE 9:e106873. doi: 10.1371/journal.pone.0106873

Dey, R., Bodennec, J., Mameri, M. O., and Pernin, P. (2009). Free-living freshwater amoebae differ in their susceptibility to the pathogenic bacterium Legionella pneumophila. FEMS Microbiol. Lett. 290, 10-17. doi: 10.1111/j.15746968.2008.01387.x

Dienst, F. T. Jr. (1963). Tularemia: a perusal of three hundred thirty-nine cases. $J$. La. State Med. Soc. 115, 114-127.

Durham-Colleran, M. W., Verhoeven, A. B., and van Hoek, M. L. (2010). Francisella novicida forms in vitro biofilms mediated by an orphan response regulator. Microb. Ecol. 59, 457-465. doi: 10.1007/s00248-009-9586-9

El-Etr, S. H., Margolis, J. J., Monack, D., Robison, R. A., Cohen, M., Moore, E., et al. (2009). Francisella tularensis type A strains cause the rapid encystment of Acanthamoeba castellanii and survive in amoebal cysts for three weeks postinfection. Appl. Environ. Microbiol. 75, 7488-7500. doi: 10.1128/AEM.01829-09

Forestal, C. A., Malik, M., Catlett, S. V., Savitt, A. G., Benach, J. L., Sellati, T. J., et al. (2007). Francisella tularensis has a significant extracellular phase in infected mice. J. Infect. Dis. 196, 134-137. doi: 10.1086/518611

Fritz, D. L., England, M. J., Miller, L., and Waag, D. M. (2014). Mouse models of aerosol-acquired tularemia caused by Francisella tularensis types A and B. Comp. Med. 64, 341-350.

Gavrilin, M. A., and Wewers, M. D. (2011). Francisella recognition by inflammasomes: differences between mice and men. Front. Microbiol. 2:11. doi: 10.3389/fmicb.2011.00011

Golovliov, I., Baranov, V., Krocova, Z., Kovarova, H., and Sjöstedt, A. (2003). An attenuated strain of the facultative intracellular bacterium Francisella tularensis can escape the phagosome of monocytic cells. Infect. Immun. 71, 5940-5950. doi: 10.1128/IAI.71.10.5940-5950.2003

Hajjar, A. M., Harvey, M. D., Shaffer, S. A., Goodlett, D. R., Sjöstedt, A., Edebro, H., et al. (2006). Lack of in vitro and in vivo recognition of Francisella tularensis subspecies lipopolysaccharide by Toll-like receptors. Infect. Immun. 74, 6730-6738. doi: 10.1128/IAI.00934-06

Hall, J. D., Woolard, M. D., Gunn, B. M., Craven, R. R., Taft-Benz, S., Frelinger, J. A., et al. (2008). Infected-host-cell repertoire and cellular response in the lung following inhalation of Francisella tularensis Schu S4, LVS, or U112. Infect. Immun. 76, 5843-5852. doi: 10.1128/IAI.01176-08 
Harb, O. S., Gao, L.-Y., and Abu Kwaik, Y. (2000). From protozoa to mammalian cells: a new paradigm in the life cycle of intracellular bacterial pathogens. Environ. Microbiol. 2, 251-265. doi: 10.1046/j.1462-2920.2000.00112.x

Hazlett, K. R., Caldon, S. D., McArthur, D. G., Cirillo, K. A., Kirimanjeswara, G. S., Magguilli, M. L., et al. (2008). Adaptation of Francisella tularensis to the mammalian environment is governed by cues which can be mimicked in vitro. Infect. Immun. 76, 4479-4488. doi: 10.1128/IAI.00610-08

Jacquier, N., Aeby, S., Lienard, J., and Greub, G. (2013). Discovery of new intracellular pathogens by amoebal coculture and amoebal enrichment approaches. J. Vis. Exp. 80:e51055. doi: 10.3791/51055

Jones, J. W., Broz, P., and Monack, D. M. (2011). Innate immune recognition of Francisella tularensis: activation of type-I interferons and the inflammasome. Front. Microbiol. 2:16. doi: 10.3389/fmicb.2011.00016

Kieffer, T. L., Cowley, S., Nano, F. E., and Elkins, K. L. (2003). Francisella novicida LPS has greater immunobiological activity in mice than $F$. tularensis LPS, and contributes to F. novicida murine pathogenesis. Microbes Infect. 5, 397-403. doi: 10.1016/S1286-4579(03)00052-2

Kingry, L. C., and Petersen, J. M. (2014). Comparative review of Francisella tularensis and Francisella novicida. Front. Cell. Infect. Microbiol. 4:35. doi: 10.3389/fcimb.2014.00035

Kumar, V., and Sharma, A. (2010). Neutrophils: cinderella of innate immune system. Int. Immunopharmacol. 10, 1325-1334. doi: 10.1016/j.intimp.2010.08.012

Lauriano, C. M., Barker, J. R., Yoon, S. S., Nano, F. E., Arulanandam, B. P., Hassett, D. J., et al. (2004). MglA regulates transcription of virulence factors necessary for Francisella tularensis intraamoebae and intramacrophage survival. Proc. Natl. Acad. Sci. U.S.A. 101, 4246-4249. doi: 10.1073/pnas.0307690101

Mares, C. A., Sharma, J., Ojeda, S. S., Li, Q., Campos, J. A., Morris, E. G., et al. (2010). Attenuated response of aged mice to respiratory Francisella novicida is characterized by reduced cell death and absence of subsequent hypercytokinemia. PLoS ONE 5:e14088. doi: 10.1371/journal.pone.0014088

Moskowitz, S. M., and Wiener-Kronish, J. P. (2010). Mechanisms of bacterial virulence in pulmonary infections. Curr. Opin. Crit. Care 16, 8-12. doi: 10.1097/MCC.0b013e3283354710

Pammit, M. A., Budhavarapu, V. N., Raulie, E. K., Klose, K. E., Teale, J. M., and Arulanandam, B. P. (2004). Intranasal interleukin-12 treatment promotes antimicrobial clearance and survival in pulmonary Francisella tularensis subsp. novicida infection. Antimicrob. Agents Chemother. 48, 4513-4519. doi: 10.1128/AAC.48.12.4513-4519.2004

Pedersen, L. L., Radulic, M., Doric, M., and Abu Kwaik, Y. (2001). HtrA homologue of Legionella pneumophila: an indispensable element for intracellular infection of mammalian but not protozoan cells. Infect. Immun. 69, 2569-2579. doi: 10.1128/IAL.69.4.2569-2579.2001

Richards, A. M., Von Dwingelo, J. E., Price, C. T., and Abu Kwaik, Y. (2013). Cellular microbiology and molecular ecology of Legionella-amoeba interaction. Virulence 4, 307-314. doi: 10.4161/viru.24290

Santic, M., Al-Khodor, S., and Abu Kwaik, Y. (2010). Cell biology and molecular ecology of Francisella tularensis. Cell. Microbiol. 12, 129-139. doi: 10.1111/j.1462-5822.2009.01400.x

Santic, M., Asare, R., Doric, M., and Abu Kwaik, Y. (2007a). Host-dependent trigger of caspases and apoptosis by Legionella pneumophila. Infect. Immun. 75, 2903-2913. doi: 10.1128/IAI.00147-07

Santic, M., Asare, R., Skrobonja, I., Jones, S., and Abu Kwaik, Y. (2008). Acquisition of the vacuolar ATPase proton pump and phagosome acidification are essential for escape of Francisella tularensis into the macrophage cytosol. Infect. Immun. 76, 2671-2677. doi: 10.1128/IAI.00185-08

Santic, M., Molmeret, M., and Abu Kwaik, Y. (2005a). Modulation of biogenesis of the Francisella tularensis subsp. novicida-containing phagosome in quiescent human macrophages and its maturation into a phagolysosome upon activation by IFN-gamma. Cell Microbiol. 7, 957-967. doi: 10.1111/j.14625822.2005.00529.x

Santic, M., Molmeret, M., Barker, J. R., Klose, K. E., Dekanic, A., Doric, M., et al. (2007b). A Francisella tularensis pathogenicity island protein essential for bacterial proliferation within the host cell cytosol. Cell. Microbiol. 9, 2391-2403. doi: $10.1111 /$ j.1462-5822.2007.00968.x
Santic, M., Molmeret, M., Klose, K. E., Jones, S., and Abu Kwaik, Y. (2005b). The Francisella tularensis pathogencity islad protein IglC and its regulator MglA are essential for modulating phagosome biogenesis and subsequent bacterial escape into the cytoplasm. Cell. Microbiol. 7, 969-979. doi: 10.1111/j.14625822.2005.00526.x

Santic, M., Ozanic, M., Semic, V., Pavokovic, G., Mrvcic, V., and Kwaik, Y. A. (2011). Intra-vacuolar proliferation of $F$. novicida within $H$. vermiformis. Front Microbiol. 2:78. doi: 10.3389/fmicb.2011.00078

Sharma, J., Mares, C. A., Li, Q., Morris, E. G., and Teale, J. M. (2011). Features of sepsis caused by pulmonary infection with Francisella tularensis Type A strain. Microb. Pathog. 51, 39-47. doi: 10.1016/j.micpath.2011.03.007

Shen, H., Chen, W., and Conlan, J. W. (2004). Susceptibility of various mouse strains to systemically- or aerosol-initiated tularemia by virulent type A Francisella tularensis before and after immunization with the attenuated live vaccine strain of the pathogen. Vaccine 22, 2116-2121. doi: 10.1016/j.vaccine.2003.12.003

Signarovitz, A. L., Ray, H. J., Yu, J. J., Guentzel, M. N., Chambers, J. P., Klose, K. E., et al. (2012). Mucosal immunization with live attenuated Francisella novicida U112DeltaiglB protects against pulmonary F. tularensis SCHU S4 in the Fischer 344 rat model. PLoS ONE 7:e47639. doi: 10.1371/journal.pone. 0047639

Simsek, H., Taner, M., Karadenizli, A., Ertek, M., and Vahaboglu, H. (2012). Identification of Francisella tularensis by both culture and real-time TaqMan PCR methods from environmental water specimens in outbreak areas where tularemia cases were not previously reported. Eur. J. Clin. Microbiol. Infect. Dis. 31, 2353-2357. doi: 10.1007/s10096-012-1576-z

Sjödin, A., Svensson, K., Ohrman, C., Ahlinder, J., Lindgren, P., Duodu, S., et al. (2012). Genome characterisation of the genus Francisella reveals insight into similar evolutionary paths in pathogens of mammals and fish. BMC Genomics 13:268. doi: $10.1186 / 1471-2164-13-268$

Sjöstedt, A. (2007). Tularemia: history, epidemiology, pathogen physiology, and clinical manifestations. Ann. N. Y. Acad. Sci. 1105, 1-29. doi: 10.1196/annals.1409.009

Thomas, V., Loret, J. F., Jousset, M., and Greub, G. (2008). Biodiversity of amoebae and amoebae-resisting bacteria in a drinking water treatment plant. Environ. Microbiol. 10, 2728-2745. doi: 10.1111/j.1462-2920.2008.01693.x

Tyson, J. Y., Vargas, P., and Cianciotto, N. P. (2014). The novel Legionella pneumophila type II secretion substrate $\mathrm{NttC}$ contributes to infection of amoebae Hartmannella vermiformis and Willaertia magna. Microbiology 160, 2732-2744. doi: 10.1099/mic.0.082750-0

Verhoeven, A. B., Durham-Colleran, M. W., Pierson, T., Boswell, W. T., and Van Hoek, M. L. (2010). Francisella philomiragia biofilm formation and interaction with the aquatic protist Acanthamoeba castellanii. Biol. Bull. 219, 178-188. doi: $10.2307 / 27899003$

Willke, A., Meric, M., Grunow, R., Sayan, M., Finke, E. J., Splettstösser, W., et al. (2009). An outbreak of oropharyngeal tularaemia linked to natural spring water. J. Med. Microbiol. 58, 112-116. doi: 10.1099/jmm.0.002279-0

Yu, J. J., Raulie, E. K., Murthy, A. K., Guentzel, M. N., Klose, K. E., and Arulanandam, B. P. (2008). The presence of infectious extracellular Francisella tularensis subsp. novicida in murine plasma after pulmonary challenge. Eur. J. Clin. Microbiol. Infect. Dis. 27, 323-325. doi: 10.1007/s10096-007-0434-x

Zogaj, X., and Klose, K. E. (2010). Genetic manipulation of Francisella tularensis. Front. Microbiol. 1:142. doi: 10.3389/fmicb.2010.00142

Conflict of Interest Statement: The authors declare that the research was conducted in the absence of any commercial or financial relationships that could be construed as a potential conflict of interest.

Copyright (c) 2016 Ozanic, Gobin, Brezovec, Marecic, Trobonjaca, Abu Kwaik and Santic. This is an open-access article distributed under the terms of the Creative Commons Attribution License (CC BY). The use, distribution or reproduction in other forums is permitted, provided the original author(s) or licensor are credited and that the original publication in this journal is cited, in accordance with accepted academic practice. No use, distribution or reproduction is permitted which does not comply with these terms. 